\title{
Studi Geokimia dan Pemodelan Kematangan Batuan Induk pada Formasi Plover, Formasi Frigate dan Formasi Echuca Shoals Cekungan Bonaparte Bagian Utara
}

\author{
Sancho da costa Amaral ${ }^{1, a}$, M. Syaifudin ${ }^{1}$, C. Prasetyadi ${ }^{1}$ \\ ${ }^{1}$ Program Studi Magister Teknik Geologi, Universitas Pembangunan Nasional Veteran \\ Yogyakarta \\ a)E-mail:Sancho.amaral93@gmail.com
}

Diterima (29 Maret 2021), Direvisi (Tanggal 23 Juni 2021)

\begin{abstract}
Abstrak Sedimen pada Formasi Plover, Frigate Echuca Shoals dipercaya sebagai batuan induk pada Cekungan Bonaparte Bagian Utara. Sampel sedimen telah dilakukan analisa geokimia dan dilanjutkan pemodelan kematangan. Kandungan total material organik dari sedimen pada formasi ini bervariasi dari 0.4-10\% TOC. Sedimen yang dianalisis memiliki nilai pemantulan vitrinit berkisar $0,4-2.8$ Ro dan nilai Tmax sebesar $350-470{ }^{\circ} \mathrm{C}$ yang mengindikasikan bahwa batuan induk pada formasi ini memiliki tingkat kematangan dari yang belum matang hingga lewat matang. Batuan induk ini didominasi oleh campuran tipe I, II, dan III yang berpotensi menghasilkan minyak dan gas dengan kandungan indek hidrogen sebesar 50-700 mg Hc/g TOC. Pemodelan 1D telah dilakukan untuk menganalisis potensi pembentukan hidrokarbon berdasarkan rekonstruksi pemendaman dan sejarah kematangan termalnya. Batuan induk Formasi Plover, Formasi Frigate dan Formasi EchucaShoals pada masa saat ini berada dalam jendela kematangan minyak dan gas mulai dari matang awal hinga lewat matang, terdapat jendela kematangan untuk gas dengan nilai pemantulan vitrinite berkisar dari 0,5-2.8. Cekungan Bonaparte bagian utara telah memiliki petroleum system yang lengkap.
\end{abstract}

Kata kunci :Analisis batuan induk, pemodelan 1D dan petroleum system.

AbstractPlover Frigate and Echuca shoalformation sediment, which is believed to be one of the major source rocksin north Bonaparte basin. Ditch cutting sample were analyzed using geochemistry analysis and followed maturity modeling. The total oeganic carbon contests of the sediment range from 0,4-10\% TOC. The sample analyzed have vitrinite reflectance in the range of 0.4-2.8 Ro and Tmax value between 350-470 ${ }^{\circ} \mathrm{C}$ which indicate that Plover, Frigate and Echuca Shoal sediments contain immature to dry gas organic matter. The sediments are dominated by type I, II, and III kerogen. Typical oil and gas generating potensial is anticipated from the sediment with fairly high hydrogen index (HI) from 50-700 mgHC/gTOC. One dimensional basin modeling was performed to analyze hydrocarbon potential and expulsion history. The source rock of the Plover, Frigate and Echuca Shoal formation at well location is presently at a stage of early to dry gas generation, gas generation with thermal maturity range from 0,5-2.8. North Bonaparte basin have complete petroleum system element, however, time of forming of element is important.

Keywords: Analysis source rock, $1 D$ modelling and petroleum system. 


\section{PENDAHULUAN}

Formasi Plover, Frigate dan Echuca Shoals di Cekungan Bonaparte bagian utara merupakan salah satu cekungan yang ada di Kawasan Timor-Leste bagian selatan tepatnya di lepas pantai (offshore) (Astuti, A., Lam, C.M. \& Fell, D. 2016 TIMOR GAP Offshore Block). Penelitian ini mencoba menganalisis kualitas, kuantitas dan tingkat kematangan batuan induk di Formasi Plover, Frigate dan Echuca Shoal untuk mengetahui potensi batuan induk. Penelitian ini juga menganalisis pemodelan cekungan 1D untuk mengetahui kapan terbentuknya migas, terbentuknya migas pada kedalaman berapa dan pada saat ini formasi apa saja yang sudah terbentuk migas. Penampang seismik digunakanuntuk mengetahui arah migrasi hidrokarbon serta mengetahui petroleum system di CekunganBonaparte. Selain itu juga digunakan data geokimia,data seismik, data stratigrafi dan data inti batuan.

\section{Geologi Regional Cekungan Bonaparte}

Cekungan Bonaparte terletak diantara paparan kontigen Australia dengan paparan Eurasia (Sundaland), berada dilepas pantai (offshore) luas area kira-kira $270.000 \mathrm{~km}^{2} \mathrm{di}$ bagian utara margin continent Australia. Luas cekungan berkisar $15 \mathrm{~km}^{2}$ pada umur Phanerozoic, sedimen carbonatedan siliciclastic dan lingkungan pengendapan laut (marine dan fluvial). Cekungan Bonaparte mengalami dua proses yaitu umur Paleozoic mengalami fase ekstensi dan fase kedua umur Akhir Triassic mengalami fase kompresi.Batas - Batas Cekungan Bonaparte terdiri dari : utara berbatasan dengan Timor Gap (offshore), selatan berbatasan dengan Darwin Australia, barat berbatasan dengan laut lepas Indonesia(Gambar 1) [5].

\section{Stratigrafi Cekungan Bonaparte Utara}

Stratigrafi cekungan Bonaparte berturut - turut dari umur tua sampai umur muda dari Precambrian sampai Quaternary pada (Gambar.2) (Williamson \& Lavering).

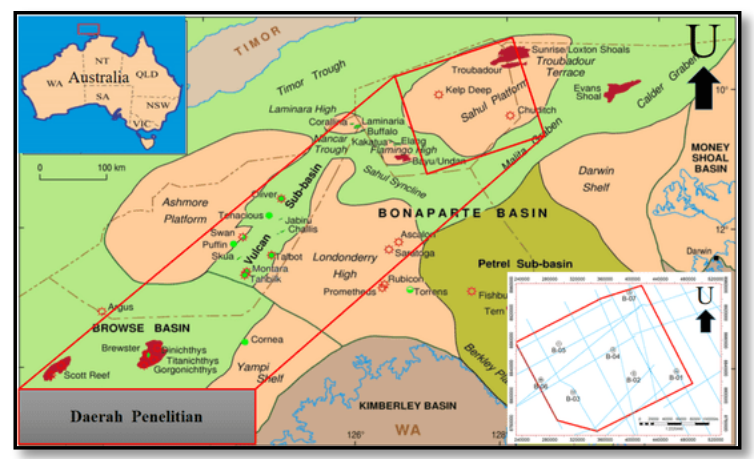

Gambar 1. Cekungan Bonaparte dan Lokasi Penelitian [1]

Susunan stratigrafi Cekungan Bonaparte bagian utara antara lain sebagai berikut:

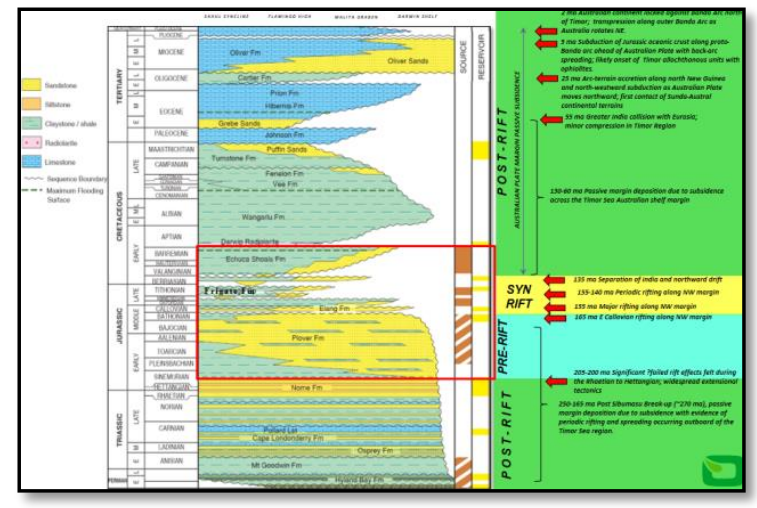

Gambar 2. Stratigrafi Cekungan Bonaparte Utara [5]

\section{Umur Permian}

Formasi Hyland Bay adalah unit sedimen tertua pada Sahul Platform hingga saat ini. Selama tahap awal eksplorasi di daerah itu, Permo-Carboniferoussecara umum dianggap oleh para penjelajah sebagai non prospektif hidrokarbon. Penemuan gas dalam formasi Hyland Baydi Kelp Deep-1 pada tahun 1997 namun 
mengubah persepsi ini setidaknya di Kelp High.

\section{Umur Triassik}

Laut transgresi di awal Triassic menunjukandeposisi marineclaystone (mat Goodwin Fm) di atas Sahul Platform dan di sebelah utara di tempat yang sekarang adalah palung timor dan pulau timor.

\section{Umur Jurassik}

Umur Jurassik bawah sampai Jurassik atas terdiri dari shale dan batupasir Formasi Plover/Frigate dan Elang equvalen Formasi.Formasi Plover sangat tebal bisa bertindak sebagai batuan induk dan batuan reservoar yang sangat baik.

\section{Umur Creataceous}

Umur Creataceous bawah sampai atas terdiri dari batuan serpih (shale stone) pada, Flamingo Frigate, Echoca Shoals, sampai Darwin. Batuan serpih sangat tebal bisa berperan sebagai bantuan induk maupun batuan penutup.

\section{Umur Tertiary}

Umur Tertiary dibagi lagi menjadi umur Paleogen dan Neogen. Paleogen terdiri dari umur Paleosen, Eosen dan Oligosen. Neogen dibagi menjadi Miosen dan Pliosen. Formasi Oliver merupakan formasi muda yang terdiri dari batugamping.

\section{METODOLOGI}

\section{Data}

Data yang digunakan dalam penelitian ini adalah data stratigrafi, data geokimia dan data seismik. Analisis data geokimia menggunakan 6 sumur.

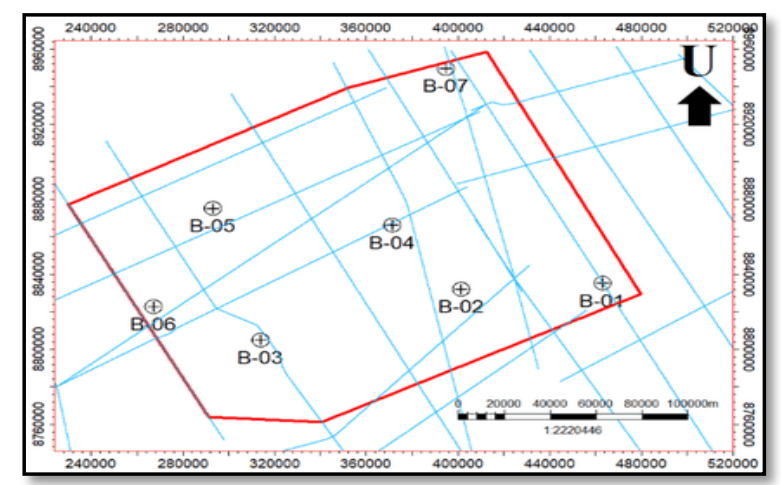

Gambar 3.Base map dan kenampakan sumur dan seismik 2D

\section{Metodologi}

Secara umum metode yang digunakan dalam penelitian ini adalah metode analisa data geokimia untuk mengetahui potensi batuan induk dan selanjutnya membuat pemodelan 1D. Data seismik untuk mengetahui arah migrasinya hidrokarbon.

\section{Analisis Batuan Induk}

Analisis dilakukan pada Sumur B01,B-02, B-03, B-04, B-05dan B-06. Untuk mengetahui kualitas, kuantitas, tingkat kematangan dan potensi batuan induk pada Formasi Plover, Formasi Frigate danFormasiEchuca Shoals.

\section{Pemodelan 1D}

Pemodelan cekungan 1D merupakan integrasi dari data ceokimia seperti data umur batuan, well top, TOC, Hi, Tmax, yang divalidasi dengan nilai Ro dan nilai BHT. Untuk mengetahui kematangan batuan induk pada awal matang, puncak matang dan akhir matang serta pada saat ini formasi apa saja yang sudah matang.

\section{Penampang seismik 2D}

Penampang seismik 2D merupakan interpretasi dari data sumur dan data seismik untuk mengetahui arah migrasi minyak dan gas bumi.

\section{HASIL PENELITIAN}

\section{Analisis Batuan Induk}

Pada Tabel 1 di bawah merupakan data geokimia pada sumur B-01, B-02, B- 
03, B-04, B-05, B-06 dan B-07. Semua data sumur tersebut memiliki data geokimia dari Rock Eval Pyrolysis. Berdasarkan Peter dan Cassa (1994), data geokimia sumur B-01, B02, B-03, B-04, B-05, B-06d an B-07 tersebut dapat digunakan untuk menentukan potensi batuan induk, total organic carbon tipe kerogen dan kematangan batuan induk yang hasilnya seperti pada Tabel 1. Tabel 1

Tabel 1. Data potensi batuan induk dari sumur B-01, B-02, B-03, B-04, B-05, B6 dan B-07.

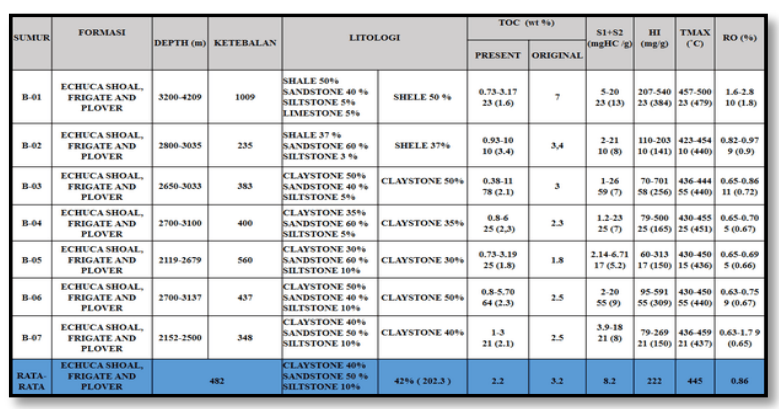

Dari Tabel 1., data-data geokimia dibuatlah ringkasan geokimia yang ditunjukkan pada Gambar 4, Gambar 5 Gambar 6, Gambar 7, Gambar 8, Gambar 9, danGambar 10. Kurva TOC vs kedalaman, $\mathrm{S} 1+\mathrm{S} 2$ vs kedalaman, $\mathrm{HI}$ vs kedalaman, Ro vs kedalaman dan Tmax vs kedalaman pada sumur B-01, B-02, B-03, B-04, B-05, B-06dan B-07 Formasi Plover,Formasi Frigate dan Formasi Echuca Shoals ditunjukkan pada daerah yang diberi kotak warna biru.

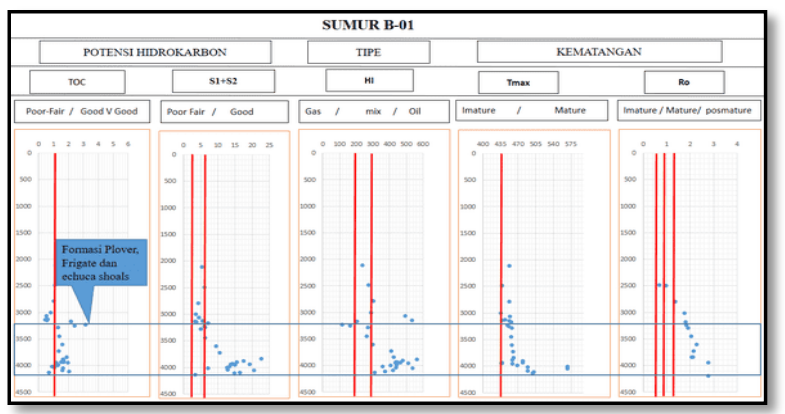

Gambar 4. Ringkasan geokimia sumur B-01 (satuan kedalaman dalam meter)

Dari Tabel 1, Gambar 4, Gambar 5Gambar 6, Gambar 7, Gambar 8, Gambar 9, danGambar 10 dapat disimpulkan bahwa Formasi Plover, Formasi Frigate dan dapat disimpulkan bahwa pada Formasi Plover, Frigate dan Echuca shoals pada Cekungan Bonaparte bagian utara memiliki potensi menjadi batuan induk yang menghasilkan hidrokarbon.

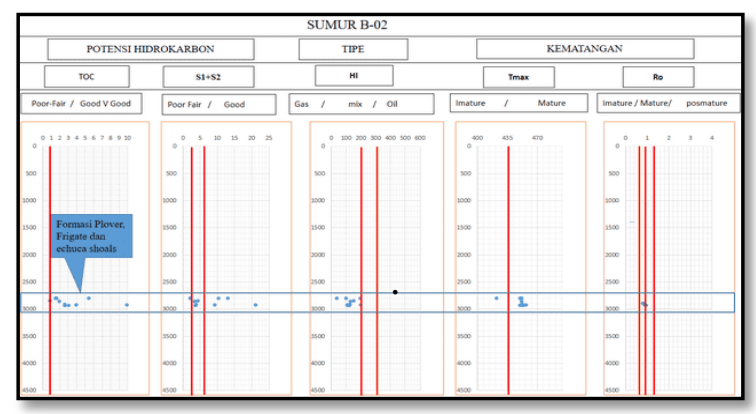

Gambar 5. Ringkasan geokimia sumur B-02 (satuan kedalaman dalam meter).

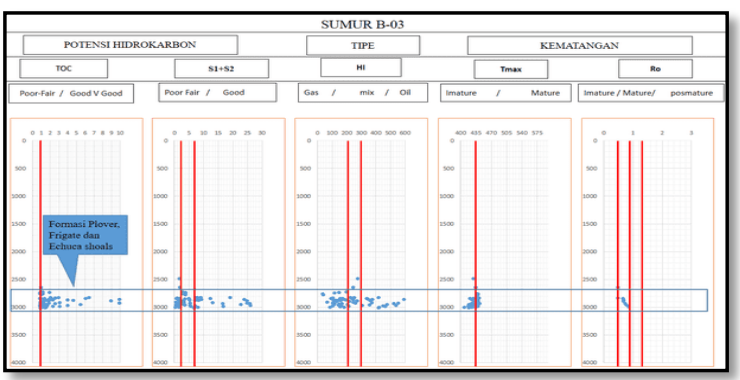

Gambar 6. Ringkasan geokimia sumur B-03 (satuan kedalaman dalam meter).

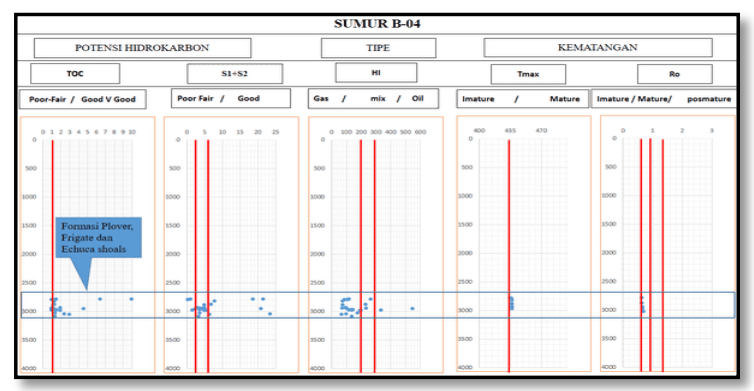

Gambar 7. Ringkasan geokimia sumur B-04 (satuan kedalaman dalam meter).

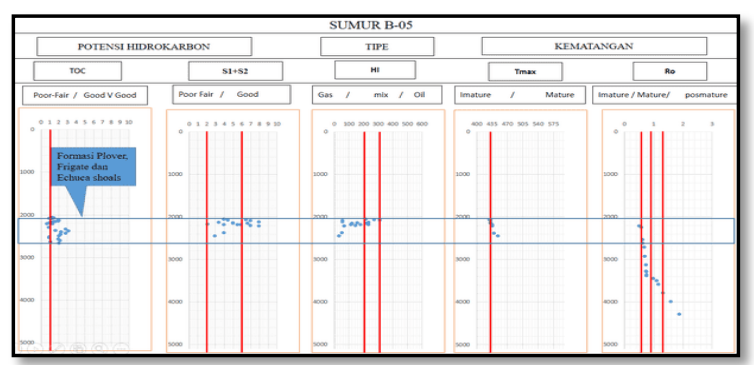

Gambar 8. Ringkasan geokimia sumur B-05 (satuan kedalaman dalam meter). 


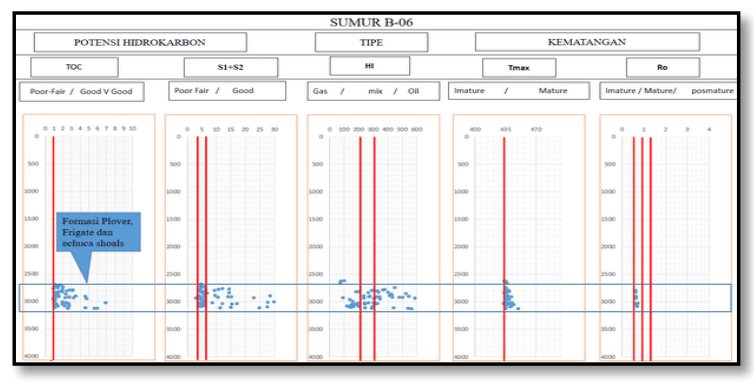

Gambar 9. Ringkasan geokimia sumur B-06 (satuan kedalaman dalam meter).

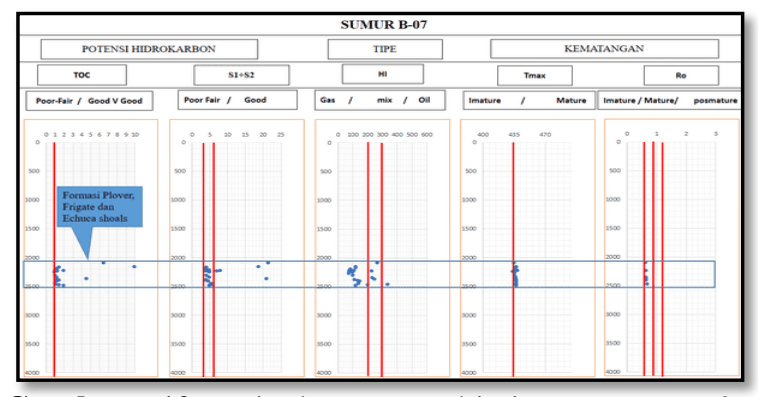

Gambar 10. Ringkasan geokimia sumur B-07 (satuan kedalaman dalam meter)

\section{Data Masukan Pemodelan}

Data masukan pemodelan meliputi komposisi lapisan batuan, data geokimia, SWIT, aliran panas(heat flow), Ro dan BHT (bottom hole temperature). Data geokimia yang diperlukan adalah TOC dan HI. TOC yang digunakan pada (Tabel 1).Data SWIT yang digunakan berdasarkanWygrala (1989) pada daerah Asia Tenggara dan dengan kinetic tipe II [2]. Data aliran panas merupakan hasil trial and error dengan mencocokkan nilai aliran bahang dari waktu ke waktu dengan garis yang memotong nilai Ro dan BHT yang paling tepat. Jika garis telah tepat memotong maka nilai aliranpanas dapat digunakan dan model sudah tervalidasi (Gambar 11).

\section{Pemodelan 1D}

Pemodelan 1D dilakukan dengan data masukan pada pembahasan sebelumnya. Berdasarkan data tersebut dihasilkan Pemodelan 1D yang menggambarkan pemendaman dan kematangan tiap lapisan pada sumur B-01,B-02, B-03, B-04, B-05, B-06 danB-07. Dengan mengunakan klasifikasi Peters dan Cassa (1994) [4].

\section{Sumur B1}

Formasi Plover 127 Ma memasuki tahap matang awal, pada umur $114 \mathrm{Ma}$ memasuki tahap matang puncak dan pada umur 92 Ma memasuki tahap matan akhir. Formasi Frigate 118 Ma memasuki tahap matang awal, pada umur 111 Ma memasuki tahap matang puncak dan pada umur $77 \mathrm{Ma}$ memasuki tahap matan akhir. Formasi Echuca Shoals 110 Ma memasuki tahap matang awal, pada umur 90 Ma memasuki tahap matang puncak dan pada umur $70 \mathrm{Ma}$ memasuki tahap matang akhir.

\section{Sumur B-02}

Formasi Plover 90 Ma memasuki tahap matang awal, dan pada umur $70 \mathrm{Ma}$ memasuki tahap matang puncak. Formasi Frigate $86 \mathrm{Ma}$ memasuki tahap matang awal, dan pada umur 67 Ma memasuki tahap matang puncak. Formasi Echuca Shoals 85 Ma memasuki tahap matang awal dan pada umur $63 \mathrm{Ma}$ memasuki tahap matang puncak.

\section{Sumur B-03}

Formasi Plover $104 \mathrm{Ma}$ memasuki tahap matang awal, dan pada umur $56 \mathrm{Ma}$ memasuki tahap matang puncak. Formasi Frigate $96 \mathrm{Ma}$ memasuki tahap matang awal, dan pada umur 35 Ma memasuki tahap matang puncak. Formasi Echuca Shoals 83 Ma memasuki tahap matang awal dan pada umur $30 \mathrm{Ma}$ memasuki tahap matang puncak.

\section{Sumur B-04}

Formasi Plover 84 Ma memasuki tahap matang awal,Formasi Frigate $78 \mathrm{Ma}$ memasuki tahap matang awal, Formasi Echuca Shoals 68 Ma memasuki tahap matang awal.

\section{Sumur B-05}

Formasi Plover 17 Ma memasuki tahap matang awal, Formasi Frigate $7 \mathrm{Ma}$ memasuki tahap matang awal, Formasi Echuca Shoals $4 \mathrm{Ma}$ memasuki tahap matang awal. 


\section{Sumur B-06}

Formasi Plover 72 Ma memasuki tahap matang awal dan pada umur $8 \mathrm{Ma}$ memasuki tahap matang puncak. Formasi Frigate $42 \mathrm{Ma}$ memasuki tahap matang awal, Formasi Echuca Shoals $28 \mathrm{Ma}$ memasuki tahap matang awal.

\section{Sumur B-07}

Formasi Plover 84 Ma memasuki tahap matang awalFormasi Frigate 78 Mamemasuki tahap matang awal, Formasi Echuca Shoals 68 Ma memasuki tahap matang awal.

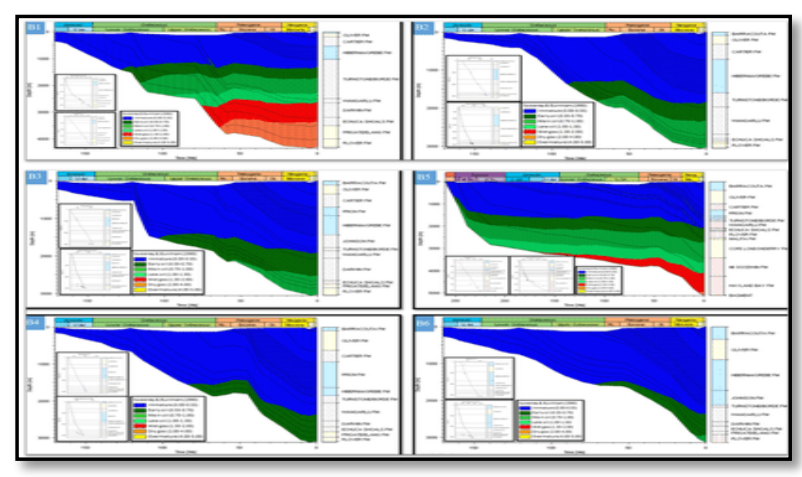

Gambar 11. Pemodelan cekungan 1D pada sumur B1, B2, B3, B4, B5 dan B6

\section{Penampang Seismik}

Penampang Seismik 2D dilakukan dengan data sumur pada pembahasan sebelumnya. Berdasarkan data tersebutdihasilkan peta kedalaman agar mengetahui arah migrasi hidrokarbon selatan ke utara (Gambar12).

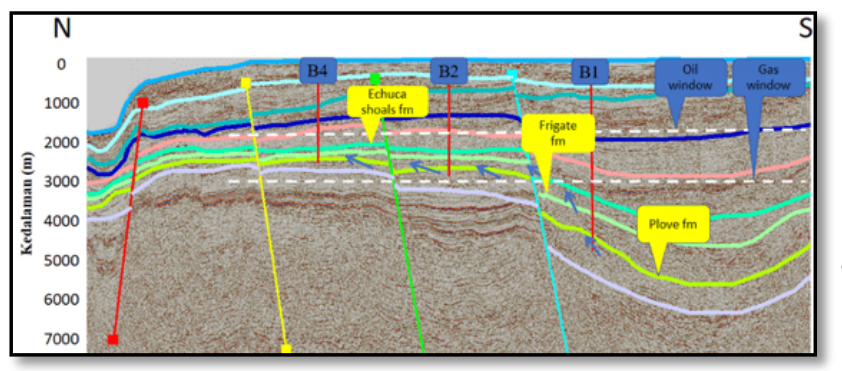

Gambar 12. Penampakan seismik arah migrasi minyak dan gas pada sumur B-01, B02 dan B-04

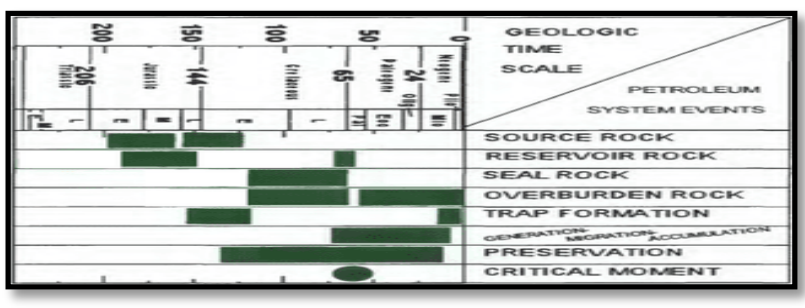

Gambar 13. Petroleum system Cekungan Bonaparte [3]

\section{Petroleum system}

Cekungan Bonaparte bagian utara telah memiliki elemen sistem petroleum yang lengkap. Selain kelengkapan sistem petroleum itu, waktu pembentukan masingmasing elemen merupakan hal yang sangatpenting. Minyak mulai terbentuk pada Kapur awal dan puncak pembentukan pada kapur Akhir sedangkan perangkap struktural mulai terbentuk pada Triassic dan Pliosen (Gambar 13).

\section{KESIMPULAN}

1. Pada semua sumur formasi yang berpotensi menjadi batuan induk adalah Formasi Plover, Frigate (JurassicTengah dan Akhir) dan Formasi Echuca Shosls (Cretaceous Awal).

2. Formasi Plover, Frigate dan Echuca Shoal memiliki TOC berkisar 0,4-10 $\mathrm{wt} \%$, tergolong buruk sampai luar biasa, tersusun atas kerogen tipe I, II dan III.

3. Pada saat ini Formasi Plover,Frigate dan Echuca shoals pada sumur B-01 berada pada kematangan lewat matang. Sedangkan di Sumur B-02 sampai B-06 berada pada kematangan awal dan puncak dikarenakan berada pada tinggian.

4. Cekungan Bonaparte bagian utara telah memiliki elemen sistem petroleum yang lengkap. Selain kelengkapan sistempetroleum itu, waktu pembentukan masing-masing elemen merupakan hal yang sangat penting. Minyak mulai terbentuk pada Kapur Awal dan puncak pembentukan pada Kapur Akhir sedangkan perangkap 
struktural mulai terbentuk pada Trias -

Pliosen.

\section{DAFTAR PUSTAKA}

[1] Barret, A.G., Hinde, A.L. and Kennard, J.M, 2004. Undiscovered Resource Assessment Methodologies and Application to the Bonaparte Basin. In: Ellis, G.K., Baillie, P.W. and Munson, T.J., Eds., Timor Sea Petroleum Geoscience, Proceedings of the Timor Sea Symposium, Darwin, 19-20 June 2003, 353-372

[2] Burnham, A.K, 1989. A simple kinetic model of petroleum formation and cracking, Lawrence Livermore National Lab Report, USA. 11.

[3] Bishop, M.G., 1999, Total Petroleum Systems of The Bonaparte Gulf Basin Area, Australia: Jurassic, Early Cretaceous-Mesozoic; Keyling, Hyland Bay- Permian; Milligans-Carboniferous, Permian, file report 99-50R, USGS, Colorado.

[4] Peters, K.E., Cassa, M.R, 1994. The Petroleum System-From Source to Trap, American Association of Petroleum Geologists Memoir 60, The American Association of Petroleum Geologists, Tulsa, Oklahoma, USA, 93-120.

[5] Timor Gap, 2018. Bonaparte Basin Stratigraphy and Tectonic History, $\mathrm{P}$ rospectivity Assessment Analysis Crocodile 3D, Timor Sea,19-20 June 2009. 